\title{
Investigation and validation of optimal cutting parameters for least surface roughness in EN24 with response surface method
}

\author{
V. Suresh Babu ${ }^{1}$, S. Sriram Kumar ${ }^{2}$, R. V. Murali ${ }^{3}$ and M. Madhava Rao ${ }^{4}$ \\ ${ }^{1 * 2,3,4}$ Department of Mechanical \& Industrial Engineering, Caledonian College of Engineering, OMAN \\ *Corresponding Author: e-mail: mechvsb@gmail.com, Tel +968-98125160
}

\begin{abstract}
Amongst the most critical quality measures that define the product quality surface roughness plays a vital role. This paper has attempted in developing an empirical second order model for the predicting the surface roughness in machining EN24 alloy steel using Response Surface Method. The experiments were conducted by varying cutting speeds, feed rates, and depths of cut in Kirloskar-Turnmaster 35, under dry cutting condition. The set response variable namely the surface roughness was measured using Surftest Mitutoyo as per Japanese standards. The cutting parameters were analyzed and optimized using Box Behnken procedure in the DESIGN EXPERT environment. The effect of process parameters with the output variable were predicted which indicates that the highest cutting speed has significant role in producing least surface roughness followed by feed and depth of cut. The optimized parameters are verified and validated through a validation experiment, which concurs with the predicted optimal value in the design of experiment and also inline to the previous researches.
\end{abstract}

Keywords: Design of Experiment (DoE), Response Surface method (RSM), ANOVA, Box Behnken Design (BBD), Central Composite Design (CCD).

DOI: http://dx.doi.org/10.4314/ijest.v3i6.12

\section{Introduction}

The surface roughness of machined components is an important design specification which has greater influence on properties such as wear resistance and fatigue strength (Onwubolu, 2005). Surface with high roughness wear more quickly and have higher friction coefficients than smooth surfaces and hence many researchers have focused their study on the analysis and optimizing the surface roughness. As per the investigations (El-Baradie, 1993) and (Bandyopadhyay and Teo, 1990), increased cutting speed has better surface quality and the productivity is maximized. Surface roughness plays an important role in many areas and is a factor of great importance in the evaluation of machining accuracy. (Palanikumar et al., 2006) has analyzed the surface roughness in machining the hard martensite stainless steel and indicated that the surface roughness is a critical parameter to the functionality of machined components and this will affect the quality of the product (Thamizhmanii et al, 2008). Many researchers have concurred that, it is a characteristic that could influence the performance of the mechanical parts and the production costs. Better surface finish is possible by controlling the parameters involved in machining.

Using Artificial neural networks (ANN) and multiple regression approaches (Asilturk and Cunkas, 2011) has predicted surface roughness of AISI 1040 steel. In their study, the surface roughness was measured during turning at different cutting parameters and the experiments were carried out with full factorial design. Amongst machining operations Turning plays an important role where a single-point cutting tool removes material from the surface of a rotating cylindrical work piece (Nalbant et al, 2007). Turning is carried on lathe that provides the power to turn the work piece at a given rotational speed and feed to the cutting tool at specified rate and depth of cut. Therefore the three important cutting parameters cutting speed $\left(\mathbf{V}_{\mathbf{c}}-\mathbf{m} / \mathbf{s e c}\right)$, feed rate $(\mathbf{f}-\mathbf{m m} / \mathbf{r e v})$ and depth of cut $(\mathbf{d}-\mathbf{m m})$ need to be optimized to achieve lowest surface roughness $\left(\mathbf{R}_{\mathbf{a}}-\boldsymbol{\mu m}\right)$ in a turning operation. The purpose of this work is to predict the optimal turning operation parameters which lead to the lowest surface roughness in the sample material of EN24 alloy steel bar stock under varying conditions using Response Surface Method. This is a mathematical and statistical technique, which is useful for modeling and analysis of problems in which output or response is influenced by several 
input variables and the objective is to find the correlation between the response and the variables investigated (Montgomery, 2001). RSM was originally developed for the model fitting of physical experiments by (Box and Draper 1954) and later adopted in other fields. RS model is formulated as a polynomial function. (Oktema et al., 2005) has utilised RSM to create RS model, by developing a computer program written in MATLAB programming language. Box-Behnken Design is normally used when performing non-sequential experiments. That is, performing the experiment only once (Mason et al., 2003). In this paper the Box Behnken (BBD) has been utilized for the designing and analysis of the experiment. Machining experiments were conducted by (Lalwani et al., 2008) based on response surface methodology (RSM) and sequential approach using face centered central composite design in finish hard turning of MDN250 steel and depicted that depth of cut is the dominant contributor to the feed force. (Khaider Bouacha et al, 2010) used RSM and conducted experiments on hard AISI 52100 bearing steel with CBN tool, the study indicates depth of cut exhibits maximum influence on cutting forces as compared to the feed rate and cutting speed. (Karin Kandananond, 2010) has presented his work to determine the optimal cutting conditions to obtain surface roughness in a turning process for AISI 12L14 Steel. The results indicate that the surface roughness is minimized when the depth of cut is set to the lowest level, while the spindle speed and feed rate are set to the highest levels. EN24 is an alloy steel with high tensile strength with good shock resistance and resistance to wear. This steel also known as 817M40, equivalent to SAE (AISI)4340 and 34CrNiMo6. This is widely utilised for the manufacture of gears, shafts and other mechanical engineering components, where good tensile and impact properties are important. The cutting parameters influencing the surface finish in EN24 is to be studied for understanding the behaviour of the material. This work studies the optimal cutting conditions to achieve the lowest surface roughness in EN24. The analysis carried out and is confirmed with the experimental verification.

\subsection{Surface Roughness - An Overview}

An investigation has revealed that when the cutting speed is increased, productivity can be maximized and, meanwhile, surface quality can be improved (Alauddin et al., 1997). Many researchers have conducted experiments to determine the effect of parameters such as average roughness $\left(\mathrm{R}_{\mathrm{a}}\right.$ ), Root Mean Square (RMS) and maximum peak to valley. The theoretical arithmetic average surface roughness $(\mathrm{mm}), f$ is the feed rate $(\mathrm{mm} / \mathrm{rev})$; $\mathrm{R}$ is the tool nose radius in $(\mathrm{mm})$.

$$
R_{a}=\frac{0.032 \times f^{2}}{R}
$$

The above formula depicts that decreasing the feed rate with increased tool nose radius provides the lowest surface roughness. A portion stretching over a reference length in the direction in which the average line extends is cut out from the roughness curve. This portion is presented in a new graph with the $\mathrm{X}$ axis extending in the same direction as the average line and the $\mathrm{Y}$ axis representing the magnitude. $R_{a}$ is represented by the equation shown below, in microns $(\mu \mathrm{m})$. Where, $L$ indicates the sample length, which is as noted in Figure 1.

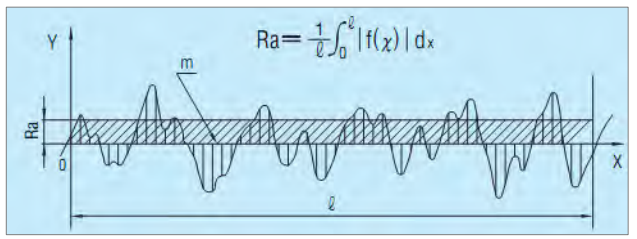

Fig 1- Arithmetical average surface roughness

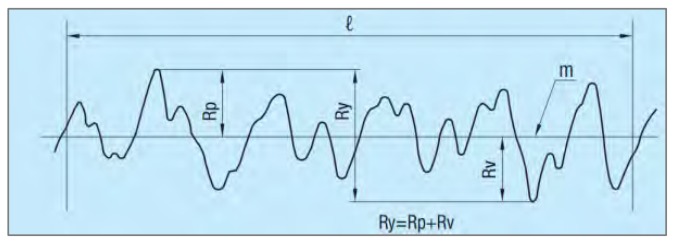

Fig 2- Maximum height Ry

$$
R_{a}=\frac{1}{l} \times \int_{0}^{l}|y(x)| d x
$$

\subsection{Maximum Height $\mathbf{R}_{\mathbf{y}}$}

Figure 2 indicates the portion stretching over a reference length in the direction in which the average line extends is cut out from the roughness curve. The gap between the peak line and the trough line is measured in the direction in which the magnitude axis extends, in $(\mu \mathrm{m})$.

\subsection{Ten Spot Average Roughness $R_{\mathrm{z}}$}

A portion stretching over a reference length in the direction in which the average line extends is cut out from the roughness curve. The average of the levels $\left(Y_{p}\right)$ of the highest peak to the fifth highest peak as measured from the average line and the average of the levels $\left(\mathrm{Y}_{\mathrm{p}}\right)$ of the lowest trough to the fifth lowest trough similarly measured in the said portion are added together. $\mathrm{R}_{\mathrm{z}}$ is this sum, in microns $(\mu \mathrm{m})$. 


\section{Methodology}

RSM is a collection of mathematical and statistical techniques that are useful for modeling and analysis of problems in which output or response is influenced by several input variables and the objective is to find the correlation between the response and the variables investigated (Montgomery, 2001). Choudhury and El-Baradie (1997) used RSM and $2^{3}$ factorial designs for predicting surface roughness when turning high-strength steel. (Box and Wilson, 1954) proposed the RSM for determining the operating conditions of chemical process with optimization of a specific response. In order to develop the response surface model, firstly the function must be assumed as a mathematical polynomial form having coefficients that should be determined. And then these coefficients are determined with applying the set of the experimental results (Box and Wilson, 1954). RSM is one of the Design of Experiments (DOE) methods used to approximate an unknown function for which only a few values are computed. These relations are then modeled by using least square error fitting of the response surface.

Two types of RSM is available for experimentation and they are Rotational Central Composite Design (RCCD) and BoxBehnken Design (BBD). A RCCD can be used when a comparatively accurate prediction of all response variable averages related to quantities measured during experimentation (Kwak et al., 2006). Box-Behnken Design is normally used when performing nonsequential experiments. That is, performing the experiment only once (Mason et al., 2003). Both of these methodologies require a quadratic relationship between the experimental factor and the responses. These designs allow efficient estimation of the first and second -order coefficients. Box-Behnken design involves fewer design points, they are less expensive to run than central composite designs with the same number of factors. Box-Behnken Design do not have axial points, thus we can be sure that all design points fall within the safe operating (Kadirgama et al., 2009). In this paper the Box Behnken (BBD) has been utilized for the designing and analysis of the experiment.

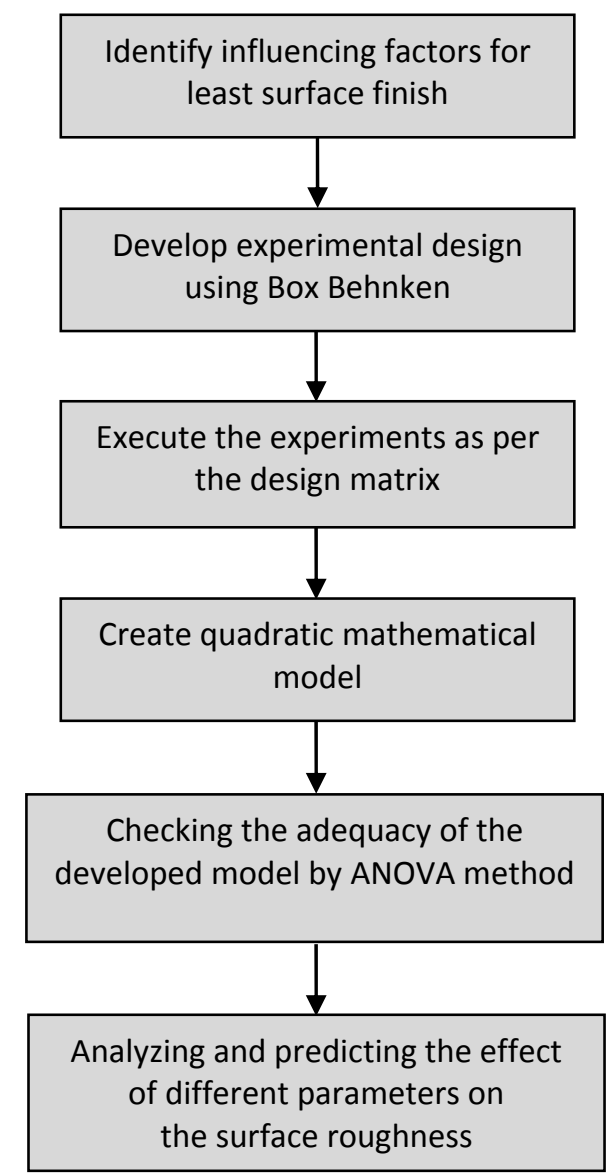

Figure 3- Proposed layout of the methodology

\subsection{Plan of Experiments}

An important stage of RS model generation by RSM is the planning of experiments. There are a large number of parameters that could be considered for machining of a particular material in Turning. However, the review of literature shows that the following three machining parameters are the most widespread among the researchers and machinists to control the turning process. In the 
present study these are selected as design factors while other parameters have been assumed to be constant over the experimental domain. As seen in Table 1, three cutting parameters the cutting speed ( $V \mathrm{c}-\mathrm{m} / \mathrm{min})$, feed $(f-\mathrm{mm} / \mathrm{rev})$, and depth of cut (d- $\mathrm{mm})$ were raised to three level as per BBD. The completed experimental design layout is in Table 2 shows a 17-trial experimental design and all the experiments were carried out randomly to minimize the effect of unexplained variability in the observed responses due to extraneous factors. The proposed layout of the methodology is depicted in the Fig 3.

Table 2 - Completed design layout

Table 1 - Cutting Parameters

\begin{tabular}{|c|l|c|c|}
\hline Notation & $\begin{array}{l}\text { Cutting } \\
\text { parameter }\end{array}$ & $\begin{array}{c}\text { Level } \\
\mathbf{1}\end{array}$ & $\begin{array}{c}\text { Level } \\
\mathbf{2}\end{array}$ \\
\hline $\mathbf{A}$ & $\begin{array}{l}\text { Cutting speed(}\left(\mathrm{V}_{\mathrm{c}}\right), \\
\text { (m/min) }\end{array}$ & 44 & 111.5 \\
\hline B & Feed(f), (mm/rev) & 0.1 & 0.5 \\
\hline $\mathbf{C}$ & $\begin{array}{l}\text { Depth of cut(d) } \\
\text { (mm) }\end{array}$ & 0.2 & 0.8 \\
\hline
\end{tabular}

\begin{tabular}{|c|c|c|c|c|c|c|}
\hline Std & Run & Block & $\begin{array}{c}\text { Factor 1 } \\
\text { A:Speed } \\
\text { “m/sec” }\end{array}$ & $\begin{array}{c}\text { Factor 2 } \\
\text { B:Feed } \\
\text { “mm/rev” }\end{array}$ & $\begin{array}{c}\text { Factor 2 } \\
\text { B:Depth } \\
\text { of cut } \\
\text { "mm” }\end{array}$ & $\begin{array}{c}\text { Response } \\
\text { 1 Surface } \\
\text { Roughness } \\
\text { “microns” }\end{array}$ \\
\hline 4 & 1 & 1 & 111.50 & 0.50 & 0.50 & 3.20 \\
\hline 7 & 2 & 1 & 44.00 & 0.30 & 0.80 & 3.80 \\
\hline 14 & 3 & 1 & 77.50 & 0.30 & 0.50 & 2.80 \\
\hline 9 & 4 & 1 & 77.50 & 0.10 & 0.20 & 2.00 \\
\hline 6 & 5 & 1 & 111.50 & 0.30 & 0.20 & 2.60 \\
\hline 1 & 6 & 1 & 44.00 & 0.10 & 0.50 & 3.10 \\
\hline 15 & 7 & 1 & 77.50 & 0.30 & 0.50 & 3.20 \\
\hline 2 & 8 & 1 & 111.5 & 0.10 & 0.50 & 1.85 \\
\hline 16 & 9 & 1 & 77.50 & 0.30 & 0.50 & 3.20 \\
\hline 10 & 10 & 1 & 77.50 & 0.50 & 0.20 & 3.15 \\
\hline 3 & 11 & 1 & 44.00 & 0.50 & 0.50 & 3.05 \\
\hline 13 & 12 & 1 & 77.50 & 0.30 & 0.50 & 3.10 \\
\hline 8 & 13 & 1 & 111.5 & 0.30 & 0.80 & 3.10 \\
\hline 17 & 14 & 1 & 77.50 & 0.30 & 0.50 & 2.80 \\
\hline 12 & 15 & 1 & 77.50 & 0.50 & 0.80 & 2.95 \\
\hline 11 & 16 & 1 & 77.50 & 0.10 & 0.80 & 3.20 \\
\hline 5 & 17 & 1 & 44.00 & 0.30 & 0.20 & 3.20 \\
\hline
\end{tabular}

Second-order response surface models were developed (Kadirgama et al., 2009), where $y^{\prime \prime}$ is the response, $x_{0}$ is dummy variable and $x_{1}$ is cutting speed, is $x_{2}$ is feed rate and $x_{3}$ is axial depth. $\beta_{0}$ is equal to $\mathrm{C}$ and $\beta_{1}, \beta_{2}$ and $\beta_{3}$ are the model parameters. The mathematical equation developed consists of 10 terms arrived from $(n+1)(n+2) / 2$, where $n=3$ is the number of factors.

$$
y^{\prime \prime}=\beta_{0} x_{0}+\beta_{1} x_{1}+\beta_{2} x_{2}+\beta_{3} x_{3}+\beta_{11} x_{1}^{2}+\beta_{22} x_{2}^{2}+\beta_{33} x_{3}^{2}+\beta_{11} x_{1} x_{2}+\beta_{12} x_{1} x_{3}+\beta_{13} x_{2} x_{3}
$$

where $y^{\prime \prime}=$ surface roughness. A portion stretching over a reference length in the direction in which the average line extends is cut out from the roughness curve. The average of the levels $\left(\mathrm{Y}_{\mathrm{p}}\right)$ of the highest peak to the fifth highest peak as measured from the average line and the average of the levels $\left(\mathrm{Y}_{\mathrm{p}}\right)$ of the lowest trough to the fifth lowest trough similarly measured in the said portion are added together. $\mathrm{R}_{\mathrm{z}}$ is this sum, in microns $(\mu \mathrm{m})$ (JIS Standard).

\section{Experimental Execution}

Experiments were carried out on a Turnmaster-35 Kirloskar lathe machine. Commercial High Speed Steel with 1/2" square was used as cutting tool. The diameter and the length of the work piece were maintained as $50 \mathrm{~mm}$ and $100 \mathrm{~mm}$ respectively. The machining parameters were limited to cutting with two levels $(44,111.5 \mathrm{~m} / \mathrm{min})$, depth of cut with two levels $(0.2,0.8 \mathrm{~mm})$, feed rate with two levels $(0.1,0.5 \mathrm{~mm} / \mathrm{rev})$. After setting up the different levels of parameter, it is conducted the experiment using the factors as indicted in the Table 3. 


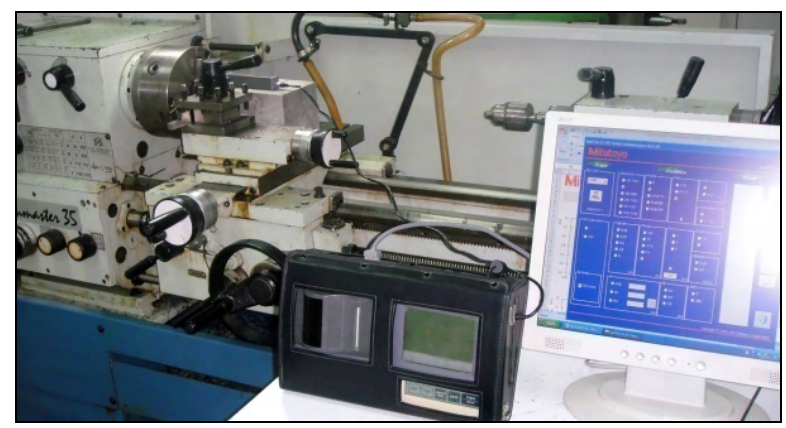

Fig4a - Experimental setup and RS232 interface

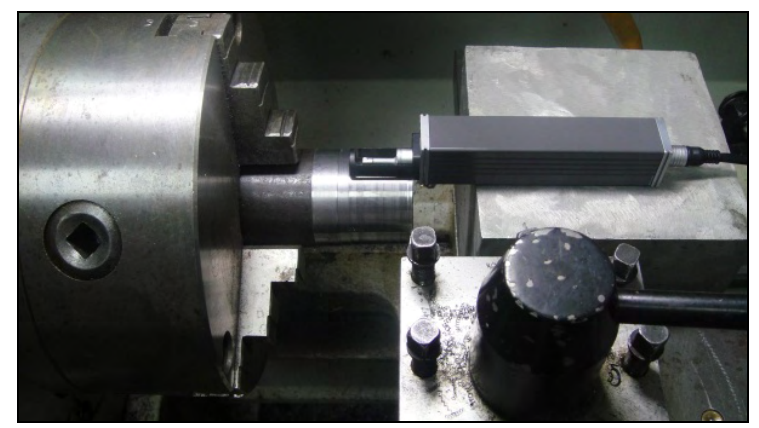

Fig4b - Experimental setup of Stylus of SURFTEST

Table 3 - Experimental Data for Average surface roughness

\begin{tabular}{|c|c|c|c|c|}
\hline Exp No & $\begin{array}{c}\text { Surface Roughness } \\
(\text { Ra) }\end{array}$ & $\begin{array}{c}\text { Surface Roughness } \\
(\text { Ra) }\end{array}$ & $\begin{array}{c}\text { Surface Roughness } \\
(\text { Ra) }\end{array}$ & $\begin{array}{c}\text { Average Surface } \\
\text { roughness (Ra) }\end{array}$ \\
\cline { 2 - 5 } & Response for Run 1 & Response for Run 2 & Response for Run 3 & Average Response \\
\hline 1 & 3.20 & 3.10 & 3.30 & 3.20 \\
\hline 2 & 3.82 & 3.85 & 3.73 & 3.80 \\
\hline 3 & 2.70 & 2.95 & 2.85 & 2.80 \\
\hline 4 & 2.01 & 2.05 & 2.1 & 2.60 \\
\hline 5 & 2.60 & 2.75 & 3.05 & 3.10 \\
\hline 6 & 3.09 & 3.2 & 3.10 & 3.20 \\
\hline 7 & 3.21 & 3.31 & 1.90 & 3.20 \\
\hline 8 & 1.85 & 1.81 & 3.26 & 3.15 \\
\hline 9 & 3.06 & 3.30 & 3.14 & 3.00 \\
\hline 10 & 3.09 & 3.21 & 3.06 & 3.10 \\
\hline 11 & 3.10 & 3.03 & 3.14 & 3.10 \\
\hline 12 & 3.06 & 3.10 & 3.16 & 2.80 \\
\hline 13 & 3.10 & 3.14 & 2.95 & 2.95 \\
\hline 14 & 2.85 & 2.7 & 3.0 & 3.20 \\
\hline 15 & 2.95 & 2.90 & 3.25 & 3.20 \\
\hline 16 & 3.15 & 3.20 & 3.14 & \\
\hline 17 & 3.41 & 3.10 & & \\
\hline
\end{tabular}

${ }^{*}$ Ra = 1/3(Run 1+Run 2+Run 3). The measured profile has been digitized and processed through the dedicated surface finish analysis software Surftest SJ-301.

\subsection{Surface Measurement}

Roughness measurement has been carried out using a portable stylus-type surface measuring instrument developed for shop floor use. SURFTEST SJ-301, Mitutoyo make is a self-contained instrument for the measurement of surface textures with variety of parameters according to various national and international standards which include JIS-B-0601-1994, JIS-B-061-1982, DIN, ISO and ANSI. Surface roughness is determined from the vertical stylus displacement produced during the detector traverse on the surface irregularities. The measurement results are displayed on digitally/graphically on the touch panel, and the output to the built in printer. Initially the instrument was calibrated with the master specimen provided. After calibration, it is setup as in Fig 4a and the machined samples were measured for smoothness at 3 different locations. The average of the three measurements of surface roughness parameter values has been recorded and used as response value in the experiment Table 3.

\subsection{Analysis of Experiment}

A commercial statistical analysis software DESIGN-EXPERT was employed for design and analyze the experiment. In DESIGN-EXPERT, RSM is used to find a combination of factors which gives the optimal response. The experimental results were analyzed with Analysis Of Variance (ANOVA), which is used for identifying the factors significantly affecting the performance measures.

\subsection{ANOVA Output}

The Anova uses different terms where, Sum of Squares is the Sum of the squared differences between the average values for the blocks and the overall mean. Degrees of freedom are generally equal to one less than the number of blocks. The mean square is the estimate of the block variance, calculated by the block sum of squares divided by block degrees of freedom. The sum of squares is the total of the sum of squares for the terms in the model, as reported in the effects list for factorials and on the Model 
screen for RSM. Mean Square is an estimate of the model variance, calculated by the model sum of squares divided by model degrees of freedom. F Value is a test for comparing model variance with residual (error) variance. If the variances are close to the same, the ratio will be close to one and it is less likely that any of the factors have a significant effect on the response. This is calculated by Model Mean Square divided by Residual Mean Square.

Table 4 depicts the Anova for cutting parameters and response. The Prob $>\mathrm{F}$ is the Probability of seeing the observed $\mathrm{F}$ value if the null hypothesis is true (there is no factor effect). Small probability values call for rejection of the null hypothesis. The probability equals the proportion of the area under the curve of the F-distribution that lies beyond the observed $\mathrm{F}$ value. The $\mathrm{F}$ distribution itself is determined by the degrees of freedom associated with the variances being compared. The present Model Fvalue of 12.96 implies the model is significant and it is noted that there is only a $0.14 \%$ chance that a "Model F-Value" this large could occur due to noise. The factors possessing the values of "Prob> F" less than 0.0500 indicate model terms are significant. In this model, the parameters A, B, C, AB, BC, $\mathrm{B}^{2}$ are significant model terms.

Table 4 - ANOVA for Cutting Parameters and Response

\begin{tabular}{|l|l|l|l|l|l|}
\hline Source & $\begin{array}{l}\text { Sum } \\
\text { of squares }\end{array}$ & Df & $\begin{array}{l}\text { Mean } \\
\text { square }\end{array}$ & F Value & P value \\
\hline Model & 3.2400 & 9 & 0.36000 & 12.96 & 0.0014 \\
\hline A-Speed & 0.7200 & 1 & 0.72000 & 25.95 & 0.0014 \\
\hline B-Feed & 0.6000 & 1 & 0.60000 & 21.80 & 0.0023 \\
\hline C-Doc & 0.5500 & 1 & 0.55000 & 19.86 & 0.0029 \\
\hline AB & 0.4900 & 1 & 0.49000 & 17.66 & 0.0040 \\
\hline AC & 0.0025 & 1 & 0.00250 & 0.090 & 0.7728 \\
\hline BC & 0.4900 & 1 & 0.49000 & 17.66 & 0.0040 \\
\hline $\mathrm{A}^{2}$ & 0.0180 & 1 & 0.01800 & 0.640 & 0.4496 \\
\hline $\mathrm{B}^{2}$ & 0.3400 & 1 & 0.34000 & 12.32 & 0.0099 \\
\hline $\mathrm{C}^{2}$ & 0.0340 & 1 & 0.03400 & 1.230 & 0.3042 \\
\hline Residual & 0.1900 & 7 & 0.02800 & & \\
\hline Lack of Fit & 0.0260 & 3 & 0.00875 & 0.210 & 0.8859 \\
\hline Pure Error & 0.1700 & 4 & 0.04200 & & \\
\hline Cor Total & 3.4300 & 16 & & & \\
\hline
\end{tabular}

\subsection{Diagnostics of the case studies}

The normal probability plots of the residuals and the plots of the residuals versus the predicted response for surface roughness and is shown in Figure 5. A check on the plots in Figure 5a reveals that the residuals fall on a straight line implying that the errors are distributed normally. The outlier points are verified by checking for any points lying outside the red lines. It is evident from the Figures 5b and 5c, all points line inside the red lines, which ensures that the model fit well.

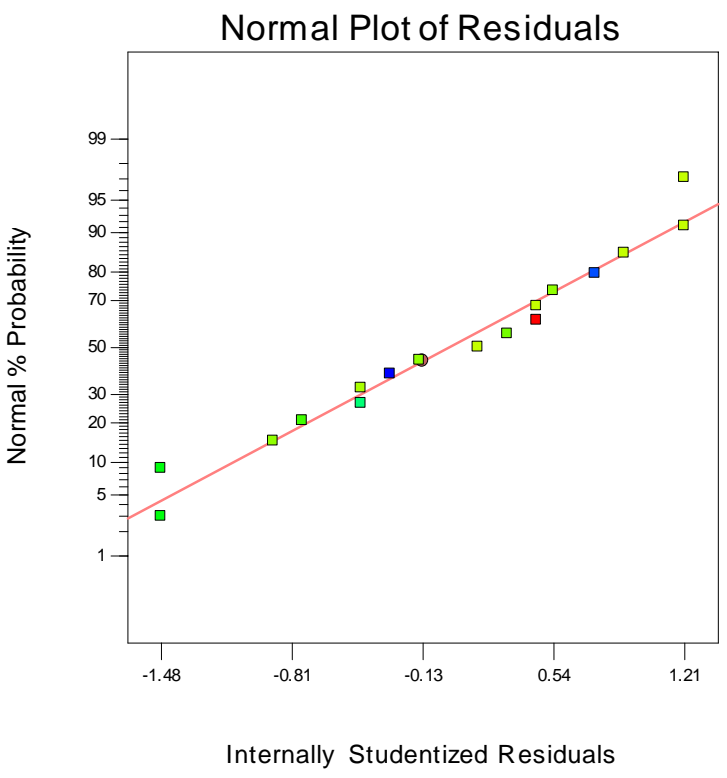

Fig 5a - Normal probability plot for residuals of $R_{a}$ data

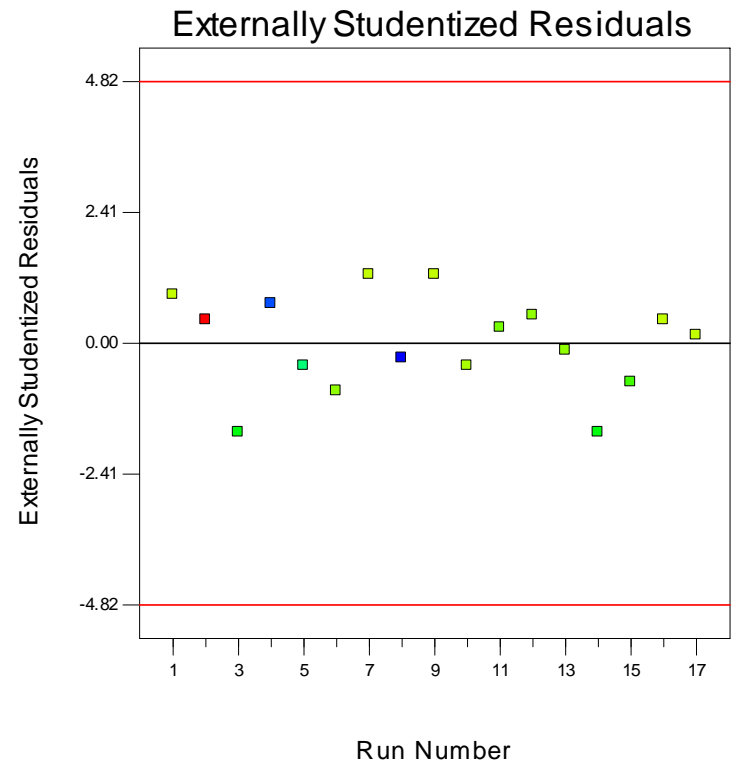

Fig 5b - Plot of residuals of predicted Vs studentized 


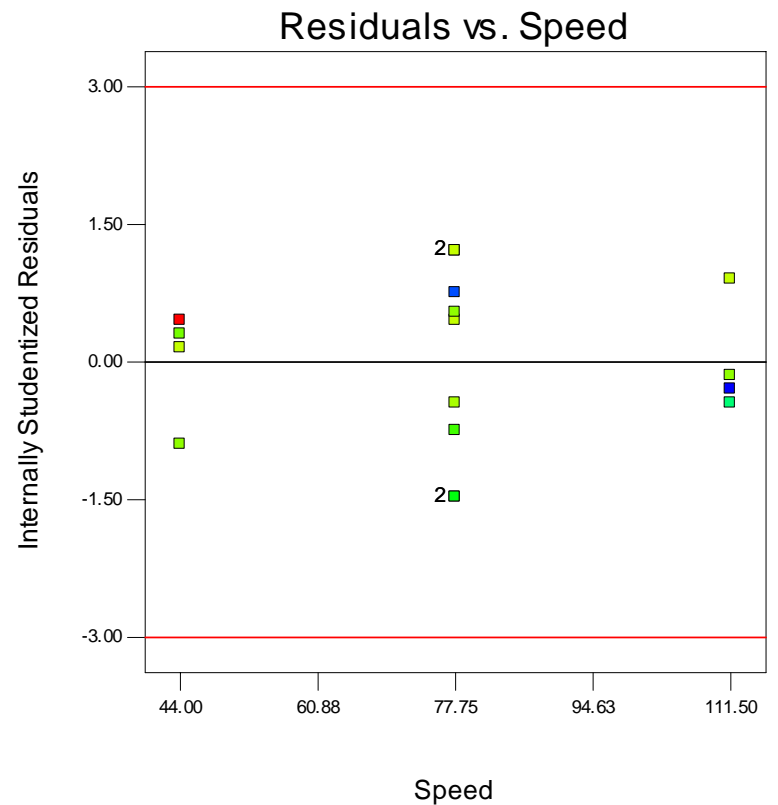

Fig 5c- Plot of residuals of predicted Vs studentized

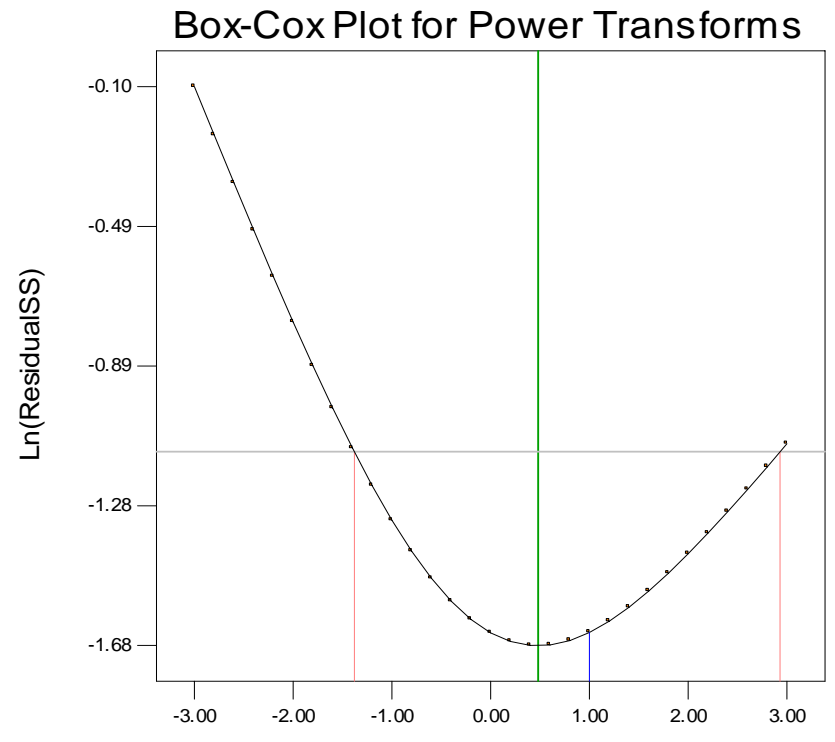

Lambda

Fig 5d - Box cox plot for transformation

As observed from the figure $5 \mathrm{~d}$, the blue line shows the current transformation. In this case it points to a value of 1 for "Lambda," which symbolizes the power applied to the response values. The observed lambda value is 1 , which indicates no transformation is required. The green line indicates the best lambda value which is 0.48 , while the red lines indicate the $95 \%$ confidence interval surrounding it. Since this $95 \%$ confidence interval includes 1 , then the model needs no transformation. The model is in the optimal zone since the blue line falls within the red lines. Therefore no change need be made in the response transformation.

Table 5 - Run by Run diagnostics

\begin{tabular}{|l|l|l|l|c|c|c|c|c|c|}
\hline $\begin{array}{l}\text { Std } \\
\text { order }\end{array}$ & $\begin{array}{l}\text { Actual } \\
\text { value }\end{array}$ & $\begin{array}{l}\text { Predicted } \\
\text { value }\end{array}$ & Residual & Leverage & $\begin{array}{l}\text { Internally } \\
\text { studentised } \\
\text { residual }\end{array}$ & $\begin{array}{l}\text { Externally } \\
\text { Studentised } \\
\text { Residual }\end{array}$ & $\begin{array}{l}\text { Inflence on } \\
\text { fitted value } \\
\text { DFFITS }\end{array}$ & $\begin{array}{l}\text { Cook's } \\
\text { Distance }\end{array}$ & $\begin{array}{l}\text { Run } \\
\text { order }\end{array}$ \\
\hline 1 & 3.10 & 3.18 & -0.075 & 0.75 & -0.900 & -0.887 & -1.536 & 0.243 & 6 \\
\hline 2 & 1.85 & 1.88 & -0.025 & 0.75 & -0.300 & -0.280 & -0.484 & 0.027 & 8 \\
\hline 3 & 3.05 & 3.03 & 0.025 & 0.75 & 0.300 & 0.280 & 0.484 & 0.027 & 11 \\
\hline 4 & 3.20 & 3.13 & 0.075 & 0.75 & 0.900 & 0.887 & 1.536 & 0.243 & 1 \\
\hline 5 & 3.20 & 3.19 & 0.012 & 0.75 & 0.150 & 0.139 & 0.241 & 0.007 & 17 \\
\hline 6 & 2.60 & 2.64 & -0.038 & 0.75 & -0.450 & -0.423 & -0.733 & 0.061 & 5 \\
\hline 7 & 3.80 & 3.76 & 0.037 & 0.75 & 0.450 & 0.423 & 0.733 & 0.061 & 2 \\
\hline 8 & 3.10 & 3.11 & -0.013 & 0.75 & -0.150 & -0.139 & -0.241 & 0.007 & 13 \\
\hline 9 & 2.00 & 1.94 & 0.062 & 0.75 & 0.750 & 0.724 & 1.255 & 0.169 & 4 \\
\hline 10 & 3.15 & 3.19 & -0.038 & 0.75 & -0.450 & -0.423 & -0.733 & 0.061 & 10 \\
\hline 11 & 3.20 & 3.16 & 0.037 & 0.75 & 0.450 & 0.423 & 0.733 & 0.061 & 16 \\
\hline 12 & 2.95 & 3.01 & -0.063 & 0.75 & -0.750 & -0.724 & -1.255 & 0.169 & 15 \\
\hline 13 & 3.10 & 3.02 & 0.080 & 0.200 & 0.537 & 0.508 & 0.254 & 0.007 & 12 \\
\hline 14 & 2.80 & 3.02 & -0.22 & 0.200 & -1.477 & -1.647 & -0.824 & 0.055 & 3 \\
\hline 15 & 3.20 & 3.02 & 0.18 & 0.200 & 1.208 & 1.257 & 0.629 & 0.036 & 7 \\
\hline 16 & 3.20 & 3.02 & 0.18 & 0.200 & 1.208 & 1.257 & 0.629 & 0.036 & 9 \\
\hline 17 & 2.80 & 3.02 & -0.22 & 0.200 & -1.477 & -1.647 & -0.824 & 0.055 & 14 \\
\hline
\end{tabular}


Table 5 indicates the diagnostics of the case studies which depicts standard order and run order noted at the extreme columns of the table. The actual and the predicted values along with the residuals are indicated in the next columns. The internally and externally studentised residuals are as seen in the column six and seven. It was also discussed at the beginning of this section that all design points lie within the limits in figure $5 \mathrm{~b}$ and figure $5 \mathrm{c}$ and no outlier was notified and hence the model was considered for further studies.

\section{Results and Discussion}

In this work, two of the three machining parameters namely cutting speed, feed rate, and depth of cut were correlated. The minimum response is achieved by using the relations as below.

The final equation for surface roughness terms of coded factors is modeled as:

$$
=3.02-(0.3) A+(0.27) B+(0.26) C+(0.35) A B-(0.025) A C-(0.35) B C+(0.065) A^{2}-(0.28) B^{2}+(0.090) C^{2}
$$

and the final equation for surface roughness in terms of actual factors is modeled as:

$$
=3.05328-(0.032083) \text { Speed }+(4.53519) \text { Feed }+(1.81698) D o C+(0.051852)(\text { Speed })(\text { Feed })-(0.0024691)(\text { Speed })(\text { DoC })
$$

$$
-(5.83333)(\text { Feed })(\text { DoC })+(0.00005)\left(\text { Speed }^{2}\right)-(7.12500)\left(\text { Feed }^{2}\right)+(1)\left(\text { DoC }^{2}\right)
$$

In this case Factor $\mathrm{A}, \mathrm{B}, \mathrm{C}, \mathrm{AB}, \mathrm{BC}, \mathrm{B}^{2}$ i.e., The cutting feed is the most significant model term followed by speed and the depth of cut. The probability value that is associated with the F Value for these terms are as in Table 4. Since these factor has a probability value less than 0.05 it is considered to have a significant effect on the response. There are not many insignificant model terms noticed in this study and analysis and hence there is no need for model reduction and improvement of the model. The "Lack of Fit F-value" of 0.21 implies the Lack of Fit is not significant relative to the pure error. There is a $88.59 \%$ chance that a "Lack of Fit F-value" this large could occur due to noise. The non-significant lack of fit is noticed in this model and hence model is good. The "Pred R-Squared" of 0.8011 is in reasonable agreement with the "Adj R-Squared" of 0.8706 . and the "Adeq Precision" measures the signal to noise ratio. This model is reported to have a ratio 14.773, which indicates an adequate signal, since the minimum required is 4 .

The surface roughness response ranges from 1.8 to 3.8. The ratio of maximum to minimum surface roughness is 2.05405, since this value is less than 3; a power transform was not required, as it will have a little effect. The study has revealed that decrease in cutting speed the roughness response value was decreased. The perturbation plot seen in Figure 5 compares the effect of the factors Speed, Feed and depth of cut at a particular point in the design space. The response is plotted by changing only one factor over its range while holding of the other factors constant. The reference point is changed to be the optimal run conditions. The optimal run conditions which provide the lowest surface finish noted from the figure 5 and figure 6 . The value is noted to be $1.38 \mu \mathrm{m}$, corresponds to the Cutting speed $(111.5 \mathrm{~m} / \mathrm{s})$, Feed $(0.1 \mathrm{~mm} / \mathrm{rev})$ and the depth of cut $(0.2 \mathrm{~mm})$. A steep slope for the factor B (The feed rate ) shows that the response is sensitive to that factor. A relatively less steep slope for other factors indicates that they are relatively less sensitive to the response .

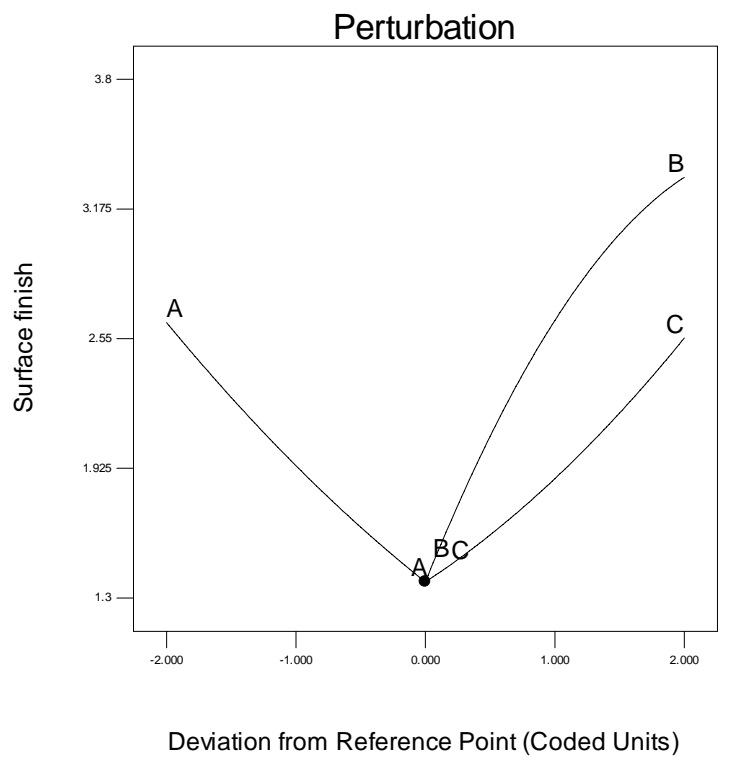

Fig 5 - Perturbation plot for the factors A, B and C 


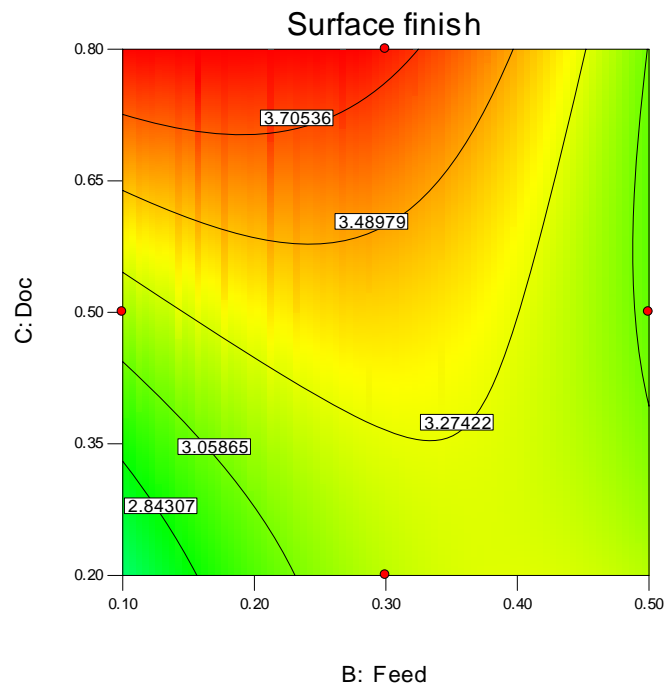

Fig 6a - Contour plot - Interaction of B and C

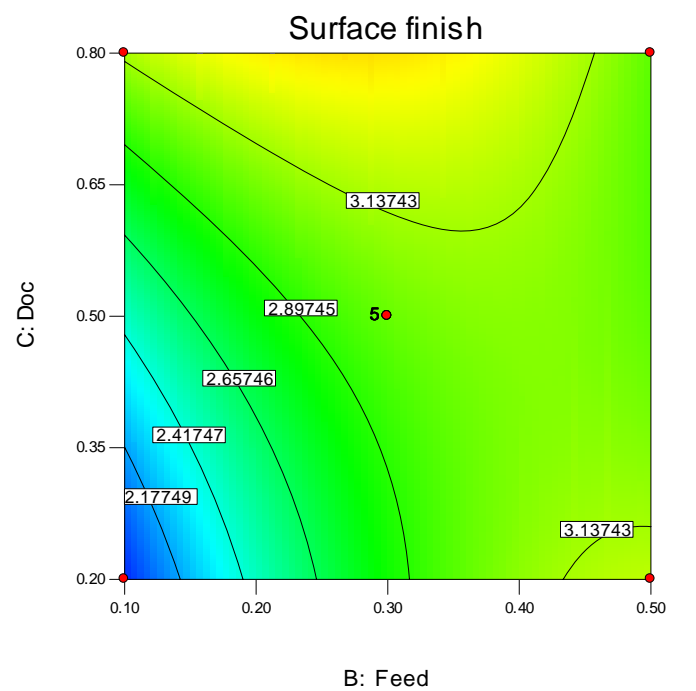

Fig $6 \mathrm{~b}$ - Contour plot - Interaction of $\mathrm{B}$ and $\mathrm{C}$

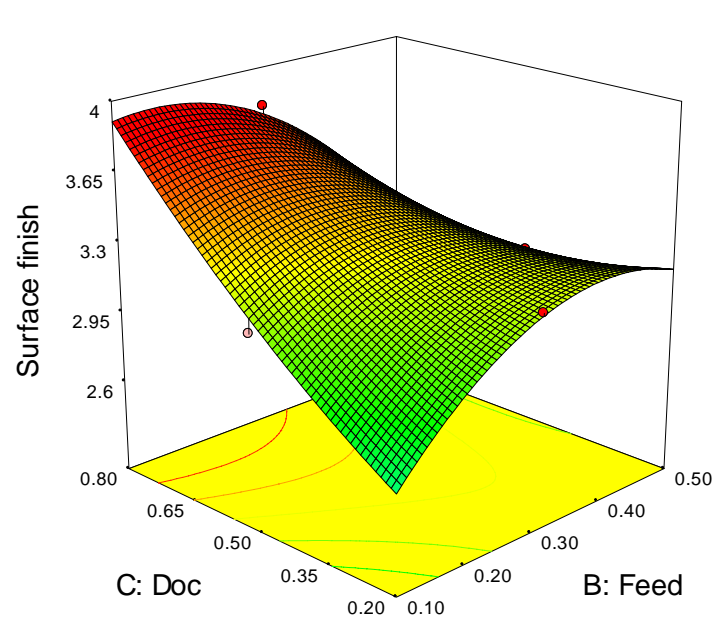

Fig 7a - 3D plot - Interaction of $\mathrm{B}$ and C

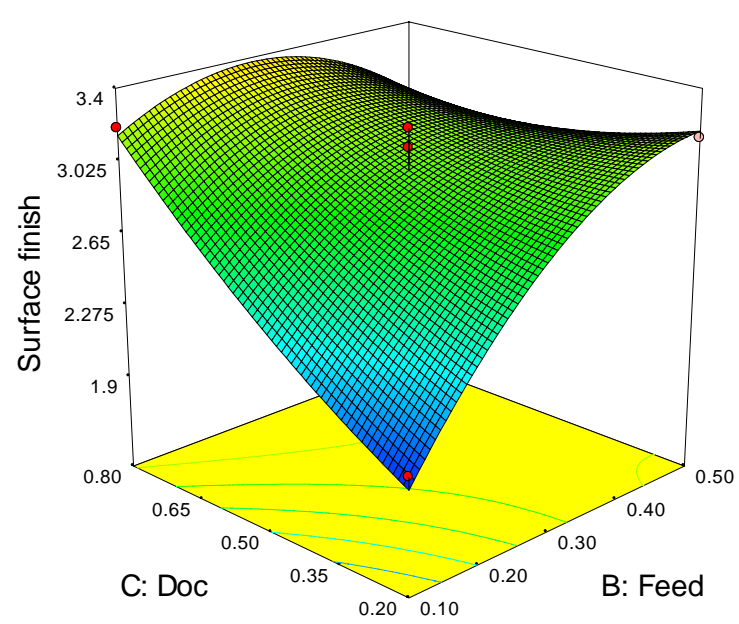

Fig 7b - 3D plot - Interaction of B and C

The surface roughness as read from the legend varies from 1.85 to 3.8 microns, which is the range of the response in the plots discussed in forthcoming sections. The study was carried out based on the legend and color coding. The figure 6a,6b,6c depicts the contour plot which is a two dimensional representation of the response for selected factors providing the interaction effect of the factors B and C with the cutting speed $44,77.5,111.5 \mathrm{~m} / \mathrm{sec}$ respectively. The corresponding the 3D plots are seen in figure 7a, 7b,7c. On observation and analysis of the contour and interaction plot $6 a$ and $7 \mathrm{a}, 6 \mathrm{~b}$ and $7 \mathrm{~b}, 6 \mathrm{c}$ and $7 \mathrm{c}$, for the factor $\mathrm{B}$ and $\mathrm{C}$, it is evident that the surface roughness pertaining to this experiment is least pronounced when the spindle speed is at 111.5 , the feed rate is 0.1 and the depth of cut is $0.2 \mathrm{~mm}$. The surface roughness corresponding to this is $1.38 \mu \mathrm{m}$. The response is very high when the Speed is maintained at low level i.e., $44 \mathrm{~m} / \mathrm{s}$. The response noticed corresponding to this is $3.85 \mu \mathrm{m}$. This is observed from figure $6 \mathrm{a}$ and $7 \mathrm{a}$. 


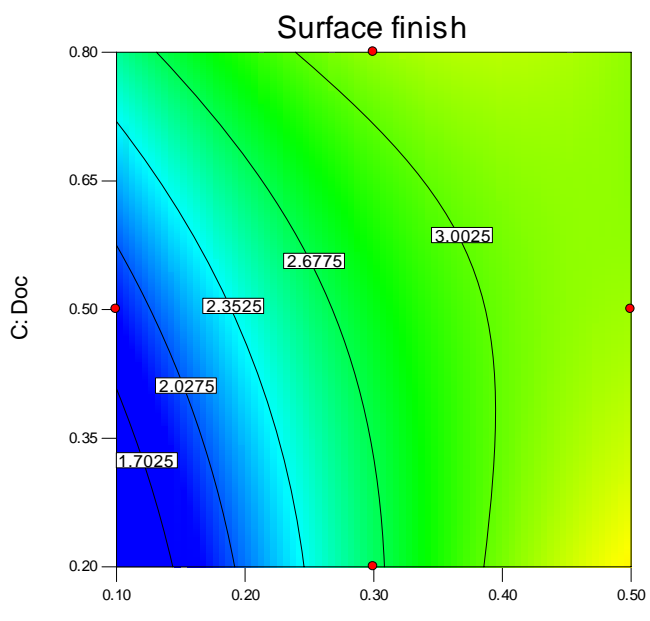

B: Feed

Fig 6c - Contour plot - Interaction of B and C

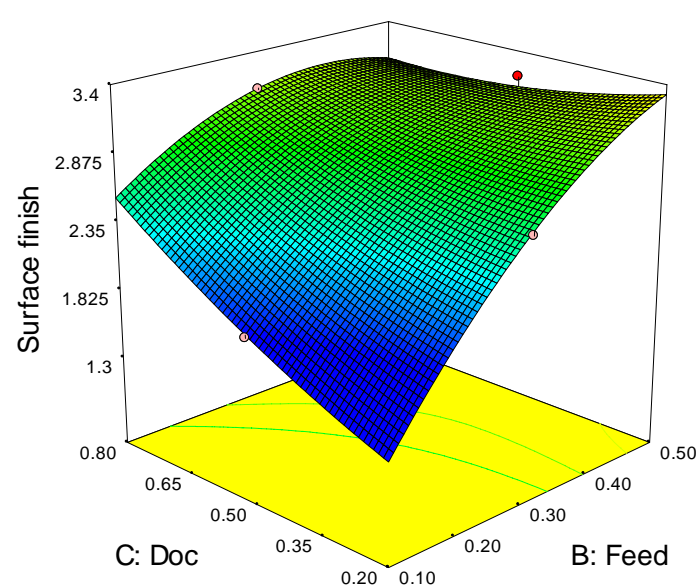

Fig 7c - 3D plot for Interaction of factors B and C

The Figures 8a, 8b, 8c depicts the contour plot which is a two-dimensional representation of the response for selected factors providing the interaction effect of the factors $\mathrm{A}$ and $\mathrm{B}$. The respective 3D plots are seen in figures 9a, 9b, 9c. On observation and analysis of the contour and interaction plot $8 \mathrm{a}$ and $9 \mathrm{a}$ for the factor $\mathrm{A}$ and $\mathrm{B}$, it is evident that the surface roughness is minimum at the cutting condition $(111.5 \mathrm{~m} / \mathrm{s}),(0.1 \mathrm{~mm} / \mathrm{rev})$ and with the depth of cut $(0.2 \mathrm{~mm})$, and the recorded of response is 1.385 microns. The figure $8 \mathrm{~b}$ and $9 \mathrm{~b}$ is the output for the cutting condition $(111.5 \mathrm{~m} / \mathrm{s}),(0.1 \mathrm{~mm} / \mathrm{rev})$ and the depth of cut $(0.5 \mathrm{~mm})$, the output response is 1.85 microns. Similarly the figure $8 \mathrm{c}$ and $9 \mathrm{c}$ is the output of the cutting condition with depth of cut as $0.8 \mathrm{~mm}$. The output recorded is highest recorded as 3.85 microns, when $(44 \mathrm{~m} / \mathrm{s}),(0.1 \mathrm{~mm} / \mathrm{rev})$ and the depth of cut $(0.8 \mathrm{~mm})$.

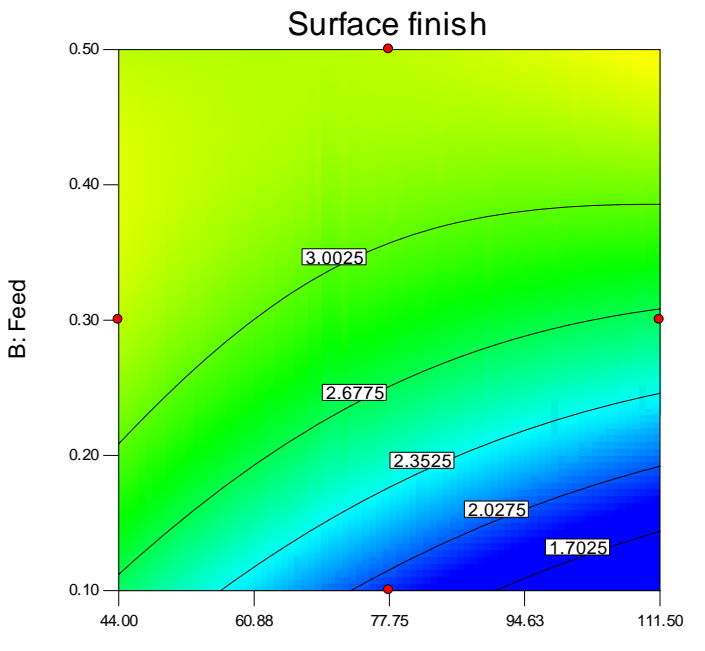

A: Speed

Fig 8a - Contour plot - Interaction A and B

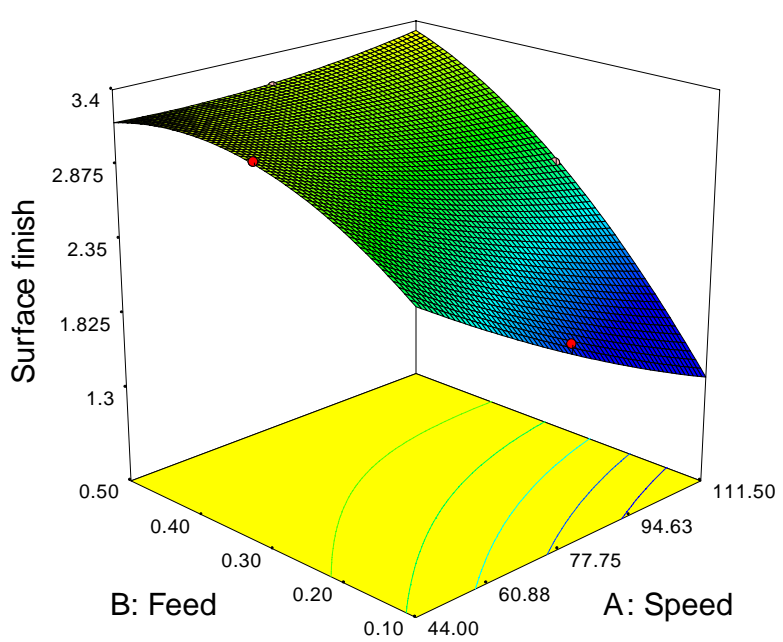

Fig 9a - 3D plot - Interaction of A and B 


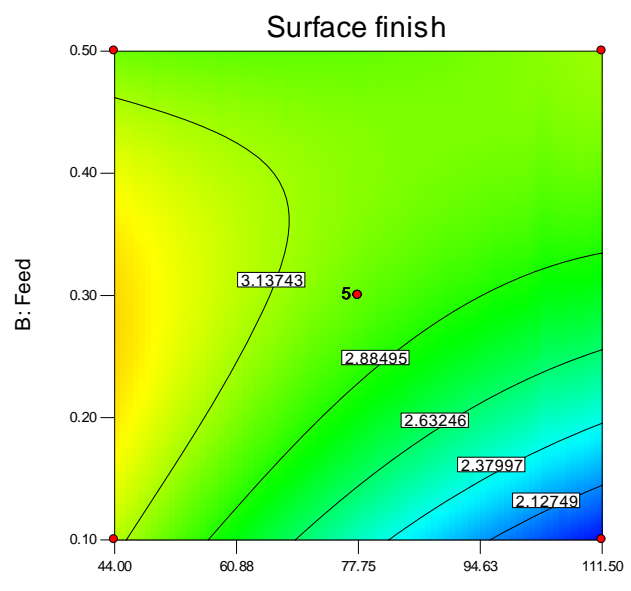

A: Speed

Fig 8b - Contour plot - Interaction of A and B

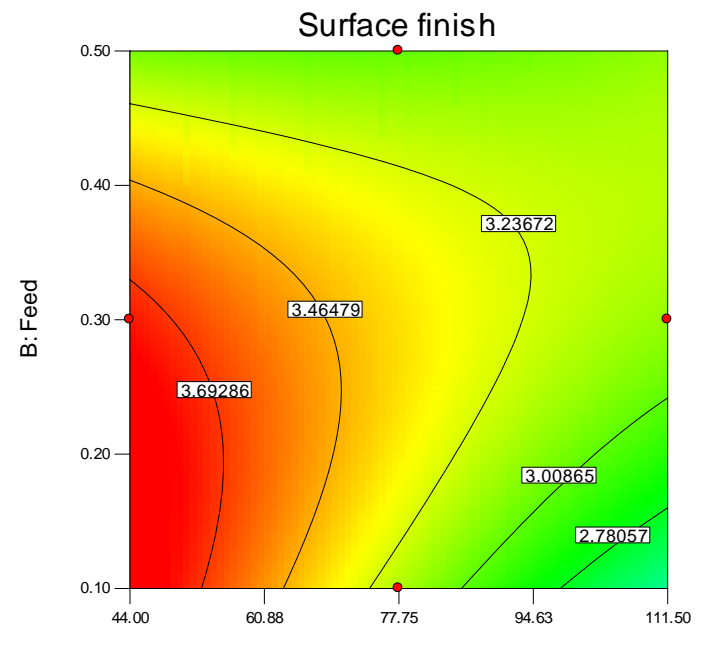

A: Speed

Fig 8c - Contour plot - Interaction of A and B

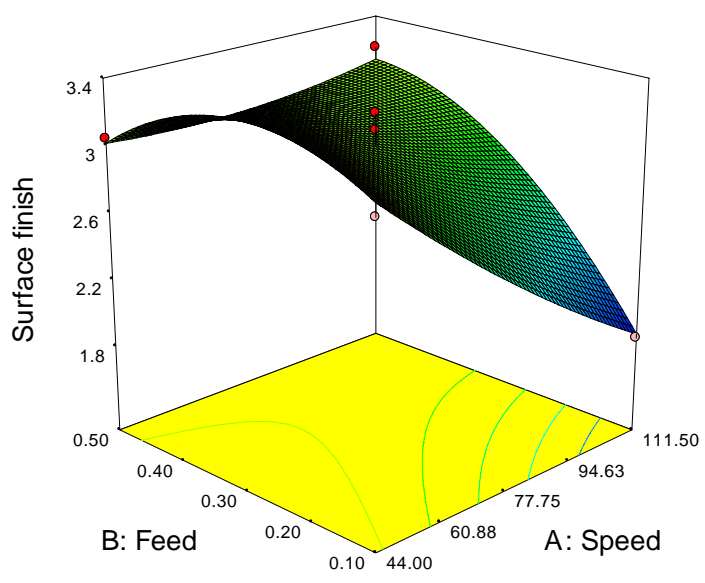

Fig 9b - 3D plot - Interaction of A and B

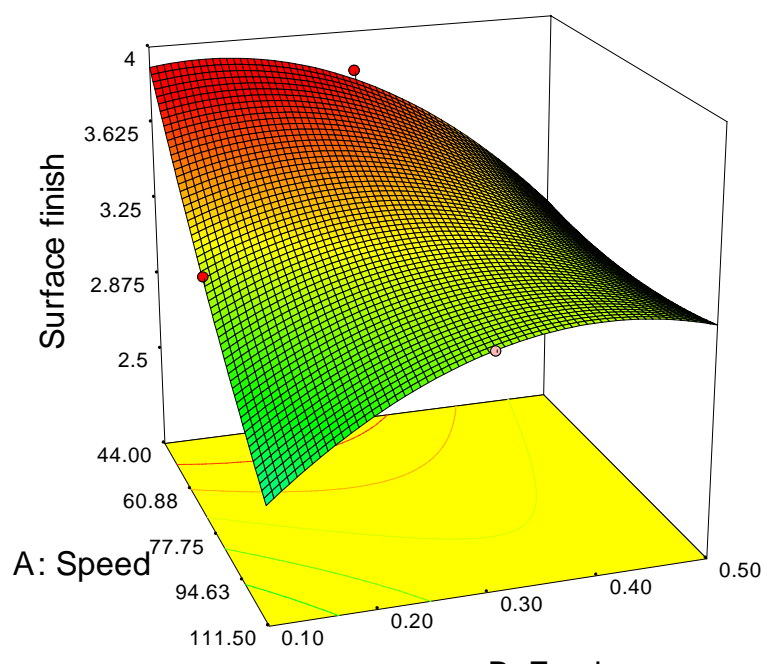

B: Feed

Fig 9c - 3D plot - Interaction of A and B

In line to the discussions, the Figures 10a,10b,10c depict the contour plot which is a two-dimensional representation of the response for selected factors providing the interaction effect of the factors A and C. The respective 3D plots are seen in figure 11a, 11b,11c. The observation and analysis of the contour and interaction plot 11a and 12a for the factor A and C indicates that the surface roughness is least pronounced when cutting speed cutting speed $(111.5 \mathrm{~m} / \mathrm{s})$, feed rate $(0.1 \mathrm{~mm} / \mathrm{rev})$ with the depth of cut $(0.2 \mathrm{~mm})$, the lowest surface roughness value is noted to be $1.385 \mu \mathrm{m}$. The response is very high when the Cutting speed is $(44 \mathrm{~m} / \mathrm{s})$, Feed $(0.3 \mathrm{~mm} / \mathrm{rev})$ and the depth of cut $(0.8 \mathrm{~mm})$, which is $3.05 \mathrm{microns}$. This is as noted in $11 \mathrm{c}$ and $12 \mathrm{c}$. 


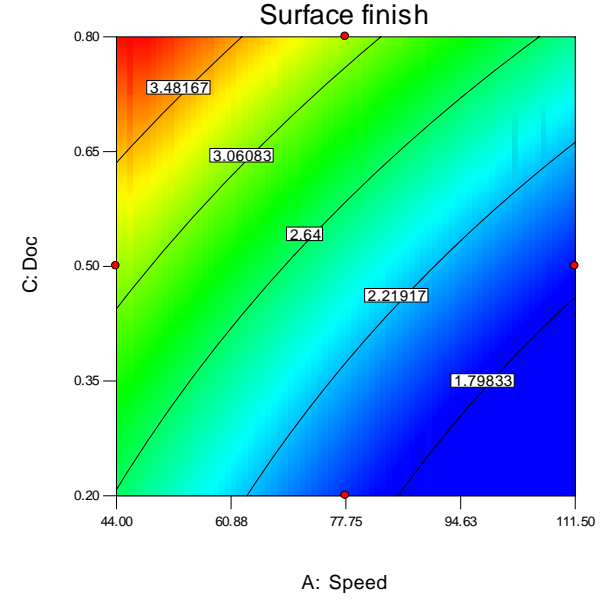

Fig 10a - Contour plot - Interaction of A and C

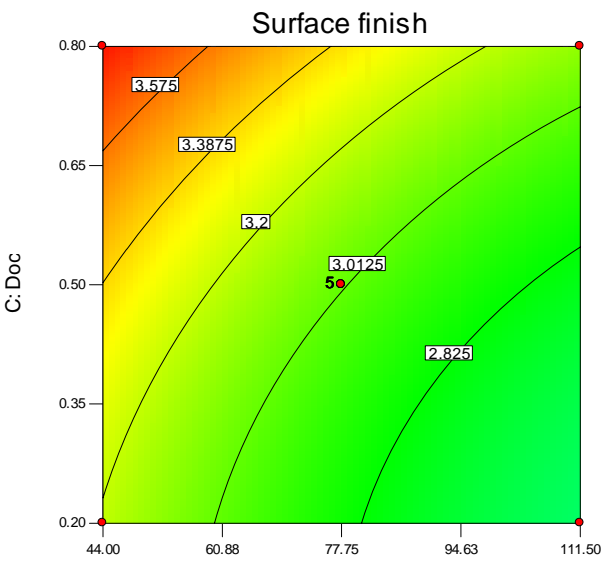

A: Speed

Fig 10b - Contour plot - Interaction of A and C

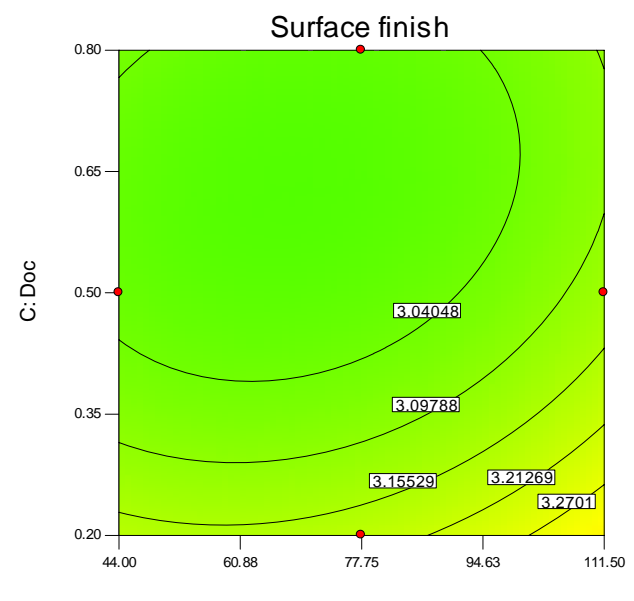

A: Speed

Fig 10c - Contour plot - Interaction of A and C

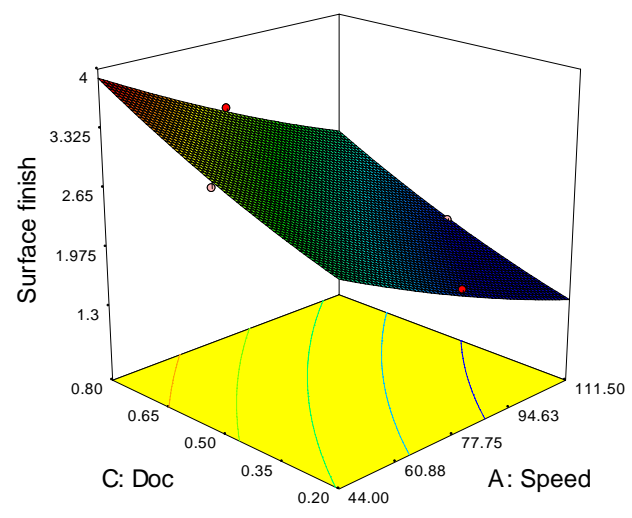

Fig 11a - 3D plot - Interaction of A and C

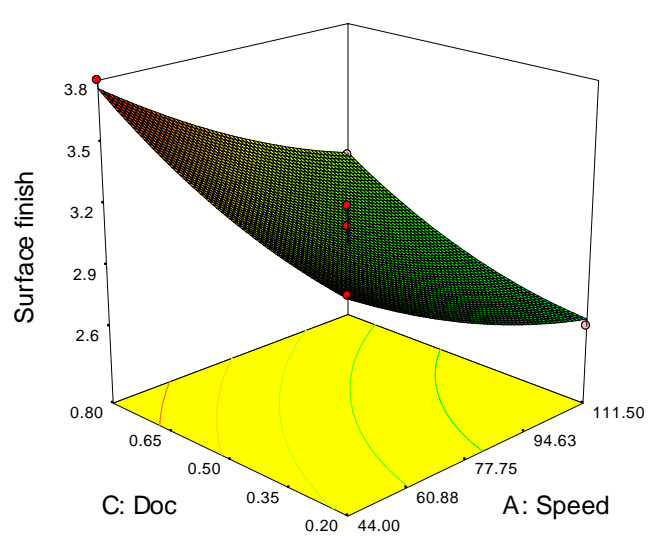

Fig 11b - 3D plot - Interaction of A and C

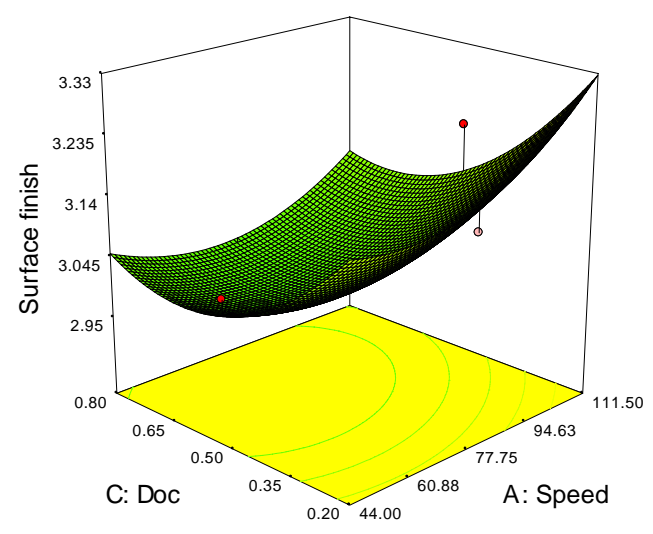

Fig 11c - 3D plot interaction of A and C 


\subsection{Validation of the experiment}

With the experimental setup, a confirmation and validation experiment was conducted using the optimal cutting parameters calculated from the study. In this the Feed rate was $(0.1 \mathrm{~mm} / \mathrm{rev})$ and cutting speed $(111.5 \mathrm{~m} / \mathrm{min})$ and of depth of cut $(0.2 \mathrm{~mm})$. Three runs of validation experiment was carried out and the average output of the measured response was noted to be 1.39microns refer figure 13. The output of the surftest was observed to fall in line with the values noted in the cube surface roughness plot referred in figure 12. It is also noted that there was a variation of 0.005 microns with the values predicted through the equations. The variation in the predicted versus the actual value of the response is so small that it was neglected. The output of the response ensures that the optimal conditions predicted through the DESIGN-EXPERT concurs with the experimental result and noted in figure 13. The empirical second order model predicted through the design was accepted to fit and accurate in the limits fixed during the design.

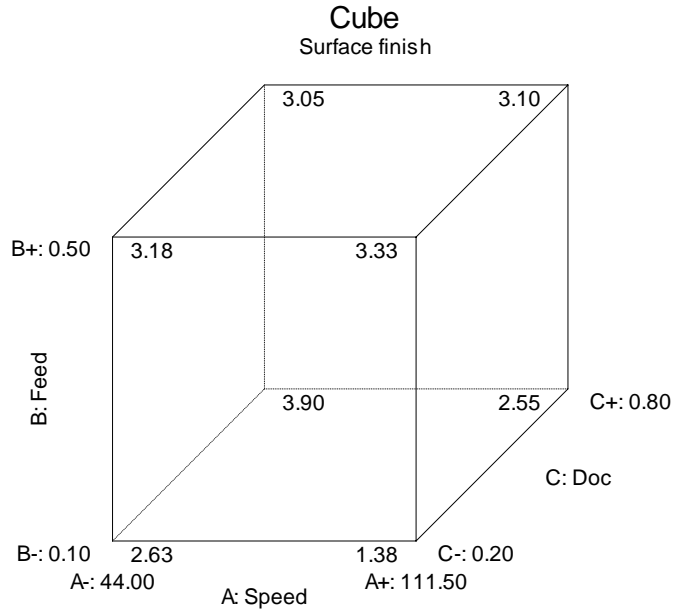

Fig 12 - Validated output for Surface Roughness

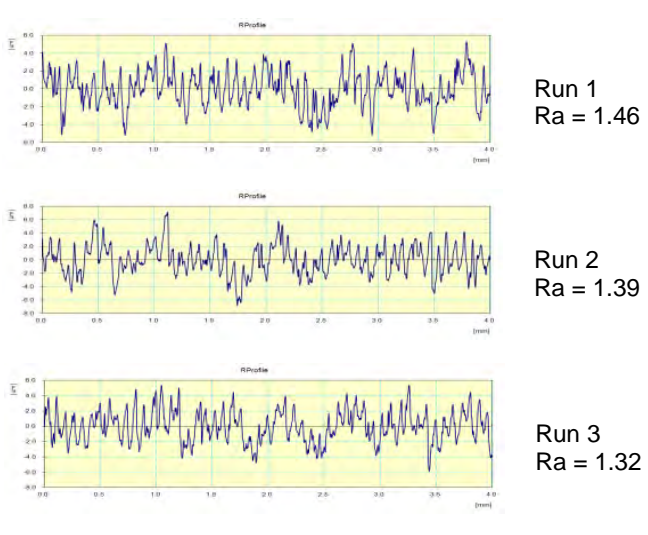

Fig 13 - Validated output for Surface Roughness

\section{Conclusions and Recommendations}

In this work the effects of the depth of cut, spindle speed, and feed rate on surface roughness were quantified using the BoxBehnken design, which is one of the most commonly used RSM techniques. A empirical second order model predicting equations for surface roughness have been developed using response surface methodology for machining EN24 with standard high speed tools. The established equations clearly show that the cutting speed is main influencing factor on the surface roughness. Based on the designed experiments from RSM and further experimental machining carried out for EN24 material, and measured from Surftest, it is concluded that the Factor B, the feed rate is the significant model term followed by cutting speed and depth of cut.

- The probability value that is associated with the F value for this term is 0.0014 . Since this factor has a probability value less than 0.05 it is considered to have a significant effect on the response, hence when it is maintained at the upper limit produces the better surface finish.

- The result falls in line to the study carried out by El-Baradie and Bandyopadhyay, Khaider Bouacha et al and other such researchers. It is concluded that the feed rate is the predominant contributor to the better surface finish followed by the spindle speed and depth of cut. The present study reflects that when the feed rate is $0.1 \mathrm{~mm} / \mathrm{rev}$ and cutting speed 111.5 $\mathrm{m} / \mathrm{min}$ and depth of cut of $0.2 \mathrm{~mm}$ the lowest surface finish is attained.

- The model validation proves that the empirical model developed is accurate and has the capability to predict the value of the response within the limits of the factors investigated.

- The quadratic models developed using RSM noticed to be reasonably accurate and can be used for predicting within the bounds of the factors investigated.

- Apart from cutting parameters considered, it was noticed machine tool vibrations, chatter and other such factors may also contributes to the poor surface roughness. Above such factors for the present analyses was not considered due to the scope of present study. The authors feel that this study will help in process improvement problem and the results obtained by this method will be useful to other researches for similar type of study and may be eye opening for further research on tool vibrations, cutting forces etc. 


\section{Acknowledgements:}

The authors sincerely wish to thank the Management and Executives of Caledonian College of Engineering, Muscat, Sultanate of Oman, for providing the facility in the laboratory for conducting the experiments. We also place our deep sense of gratitude to the reviewers for their valuable comments for the improvement of this work.

\section{References}

Alauddin, M, El Baradie M.A. and Hashmi M.S.J.. 1997. Prediction of tool life in end milling by response surface methodology, Journal of Materials Processing and Technology, 71, pp. 456-465

Asilturk I., Cunkas M., 2011, Modeling and prediction of surface roughness in turning operations using artificial neural network and multiple regression method, Expert Systems with Applications, Vol. 38, pp. 5826-5832

Bandyopadhyay. B.P. and Teo E.H. 1990. Application of factorial design of experiment in high speed turning. Proc. Manuf. Int. Part 4,Advances in Materials \& Automation, Atlanta, GA,USA, ASME, NY, pp. 3-8.

Bouacha K., Yallese M.A., Mabrouki T., Rigal J.-F., 2010, Statistical analysis of surface roughness and cutting forces using response surface methodology in hard turning of AISI 52100 bearing steel with CBN tool, International Journal of Refractory Metals \& Hard Materials 28, pp.349-361.

Box G.E.P, Wilson KB. 1954. The exploration and exploitation of response surfaces: some general considerations and examples. Biometrics; 10:16-60.

Box G.E.P., Draper N.R. 1987. Empirical model-building and response surface, John Wiley and Sons, Inc., New York, USA.

Choudhury I.A., El-Baradie M.A., 1997. Surface roughness prediction in the turning of high-strength steel by factorial design of experiments, Journal of Material Process Technology, Vol. 67, pp.55-61.

Designexpert software: http://www.statease.com/dx8descr.html

El-Baradie. 1993. Surface roughness model for turning grey cast iron (154 BHN). Proc. IMechE, 207, pp. 43-54.

JIS Standard B601-1994, JIS B0031-1994 pp. 2839-2840.

Kadirgama K., Noor M. M. etal. 2009. Surface roughness prediction model of 6061-T6 aluminium alloy machining using statistical method, European Journal of Scientific Research, Vol.25, No.2, pp. 250-256.

Kandananond K.. 2010. Using the response surface method to optimize the turning process of AISI 12L14 steel, Advances in Mechanical Engineering, , 6p.

Kwak J.-S., Sim S.-B., Jeong Y.-D., 2006. An analysis of grinding power and surface roughness in external cylindrical grinding of hardened SCM440 steel using the response surface method, International Journal of Machine Tools and Manufacture Vol. 46, pp.304-312.

Lalwani D.I., Mehta N.K., Jain P.K., 2008. Experimental investigations of cutting parameters influence on cutting forces and

surface roughness in finish hard turning of MDN250 steel, Journal of materials processing technology 206, pp.167-179

Mason R. L., Gunst R. F, D., Texas, and Hess J. L.. 2003. Statistical design and analysis of experiments with applications to engineering and science. 2nd Edition, John Wiley and Sons Publication.

Montgomery D. C., 2001. Design and Analysis of Experiments, John wiley and Sons Inc.

Nalbant M., Gokkaya H., Sur G. 2007. Application of Taguchi method in the optimization of cutting parameters for surface roughness in turning International Journal of Materials and Design, Vol. 27, pp.1379-1385.

Oktema H., Erzurumlu T., Kurtaran H.. 2005. Application of response surface methodology in the optimization of cutting conditions for surface roughness, Journal of Materials Processing Technology, Vol. 170, pp.11-16

Onwubolu G.C.. 2005. A note on surface roughness prediction model in machining of carbon steel by PVD coated cutting tools, American Journal of Applied Sciences, Vol. 2, No. 6, pp. 1109-1112.

Palanikumar, L, Karunamoorthy.R, Karthikeyan.I. 2006. Assessment of factors influencing surface roughness on the machining of glass-reinforced polymer composites, Journal of Materials and Design, Vol. 27, pp. 862-871.S.

Thamizhmanii, B. Omar B., Saparudin S. and Hasan S. 2008. Surface roughness analyses on hard martensitic stainless steel by turning, Journal of Achievements in Materials and Manufacturing, Vol. 26, No. 2, pp. 139-142.

\section{Biographical notes}

V. Suresh Babu received his Bachelor's degree in Mechanical Engineering from Bharathiar University, Coimbatore, India in 1989 and Masters in Engineering Design from Anna University, Chennai, India in 2004. He has more than two decades of experience which includes a blend of academics and Industry. He holds an Indian patent and its official journal publication. Published papers in international journal and conferences. His specific experience and areas of interest include Design \& manufacture of Gears, Gearboxes, reverse engineering and developing special purpose machines. He is member in Institution of Engineers (India), Indian Society of Technical Education(India). Presently he is working as faculty in the department of mechanical and Industrial Engineering in Caledonian college of Engineering, Muscat, Sultanate of Oman.

S. Sriram Kumar is a Mechanical Engineering Graduate working as faculty in Caledonian college of Engineering, Muscat, Sultanate of Oman. He holds a bachelor degree from Anna University, Chennai, India. He is having 7 years teaching experience and 3 years industrial experience. His research interests include CAD/CAM, Machine Design and Metal cutting problems. He has communicated papers for International journals which are under review. He has attended National and International conferences. 
R. V. Murali is a Mechanical Engineering graduate working as Senior Faculty at Caledonian College of Engineering, Sultanate of Oman. He holds a master degree in Manufacturing Technology in the year 1996 from India. He is having 10 years of teaching and research experience, 2 years of software industry experience. He has 3 international journal papers, 4 international conference papers and 2 national level conference papers to his credit. He is currently pursuing his PhD programme in manufacturing engineering and his research expertise includes cellular manufacturing, virtual cellular manufacturing focusing on empirical aspects.

M. Madhava Rao is a senior faculty in the Department of Mechanical and Industrial Engineering, Caledonian college of Engineering, Sultanate of Oman. He has more than 30 years of teaching and industrial experience. His current area of research included operations management and Quality Engineering. He has attended National and International conferences. He is a member of Oman Society of Engineers (Sultanate of Oman).

Received May 2011

Accepted October 2011

Final acceptance in revised form November 2011 